\title{
McDonaldisation and the Labour Process:
}

\section{Impacts and Resistance}

\author{
Yu-Jen $\mathrm{Wu}$ \\ The Department of Labour Relations \\ National Chung Cheng University \\ Minghsiung 62102, Taiwan \\ Tel: 886-5-272-0411 ext.32352Ｅ-mail: labyjw@ccu.edu.tw
}

This paper was an integral part of my study sponsored by National Science Council, Taiwan, under HSC 94-2416-H-194-016.

\begin{abstract}
McDonaldisation is the process by which the principles of the fast-food restaurant are coming to dominate more and more sectors of society. The aims of this article are to explore the possible impacts of McDonaldisation on the labour process and expose the hidden agenda behind McDonaldisation. My main argument is that McDonaldisation is the realization of an extremely instrumental rationality which deliberately develops a variety of strategies to achieve the interests of capital. The article indicates that, despite the prevailing of McDonaldisation, there might be two forces that seems likely to drive the labour process away from the McDonaldised working rules: subjectivity and flexibility. The article is concluded that McDonaldisation is gradually blurring and even eroding the boundary between the customers and the workers. The customers used to be the source of profit-making but are now asked to a part of the labour force, that is an exploitation of the customers to supplement McDonaldisation in the exploitation of labours.
\end{abstract}

Keywords: McDonaldisation, Labour Process Theory, Managerial Strategy, Rationality

\section{Introduction}

The modes of labour processes vary from industrial society to industrial society, but under capitalist economy it shares some distinguish features. One of the most notable characteristic is derived from what Marx called the transformation of labour power into labour. In the process of transformation, capital needs to create an appropriate environment which brings labour into full play in order to maximise profit. However, the interest of workers is pursuing job security, higher pay, and satisfactory working environment. Workers may resist against various managerial strategies through informal job control and restricted output of production (Thompson and McHugh 1990:113). Faced with the pressures of competition from global market, capital must develop new form of strategies of control in an attempt to smooth the transformation of labour power. Under the system of capitalism, the major function of management is to make the owner of capital to gain profits by maximizing the use of labour power (Berkeley Thomas 1993:61) In the modern time, the development of scientific management strategies further reinforces the control over labour power and work places (Braverman 1998). In this context, the McDonald's fast-food chain emerges and, then, spreads all over the world.

Ritzer's $(1998,2007)$ concepts of the McDonaldisation thesis are innovative and insightful, arguing that contemporary life is succumbing to the rationalisation, routinisation, and predictability. After deliberate examinations on two of Ritzer's works on McDonaldisation, I find some weaknesses that need to be further addressed and analysed. Firstly, in terms of research approaches, Ritzer tried to link McDonaldisation with the labour process in his both works. However, the studies cannot show how and the extent to which McDonaldisation shapes the features of the labour process. Secondly, Ritzer's analysis is inevitably deterministic, hence, it was unable to explore the dynamic social process and work relations. Most importantly, Ritzer ignores the subjectivity of workers in the production process which is derived from the contradiction between capital and labour. Drawing on these weaknesses, I argue that subjectivity of workers and the dynamic process of labour-capital relations would operate to reduce the influence of McDonaldisation on the daily working life. 
The aim of the article is to explore the extent to which McDonaldisation shapes the dynamic social relations at work by revealing its impacts on the labour process. And, it tries to draw theoretical implications from the resistance of McDonaldisation in an attempt to provide critical insights into the McDonaldisation thesis. To achieve the objectives, the article is divided into four sections. The first addresses the dimensions of the McDonaldisation thesis. The second explores the possible impacts of McDonaldisation on the labour process. The third engaged in a critical appraisal of McDonaldisation. The final part is concluded that McDonaldisation not only reinforces the degree of managerial control over, but expand the range of capitalist exploitation from workers to the "unpaid labour" - the customers.

\subsection{Dimensions of the McDonaldisation Thesis}

Prior to addressing McDonaldisation of labour process, it is necessary to clarify what is McDonaldisation. As Ritzer (2007: 1) puts it simply, "McDonaldisation is the process by which the principles of the fast-food resaurant are coming to dominate more and more sectors of American society as well as of the rest of the world." In essense, McDonaldisation is an effective paradigm of culture, value, operation concept, serving principles, and work arrangements. To some extent, the influence of McDonaldisation is not restricted to the restaurant business, it has invaded many aspects of modern life namely industries, services, government sectors, education, family and work.

At McDonald's workplaces, interactions and activities among the workers, the managerial staffs, and the consumers are of the nature of rationality and rationalization. The sense of McDonaldisation embraces four aspects, efficiency, calculability, predictability, and control (Ritzer 1998, 2007). These aspects constitute the conceptual framework of McDonaldisation. However, in Ritzer's works, he merely addresses them in general and pays little attention to the dynamic process of employee relations. In this section, I intend to take Ritzer's work a step further, that is to systemically and deliberately elaborate the main elements of McDonaldisation by focusing on the actual working process of McDonald's. This helps to make better connections between McDonaldism and the labour process.

\subsection{Efficiency}

Efficiency implies the use of an optimal method in achieving a given aim. Under the scientific management of Taylorism, each working process and activities are carefully calculated and evaluated by adopting "one best way" arrangement to carry out the process of production. In order to achieve the demands of efficiency, there are three special processes or arrangements in the world of McDonald's: streamlining the process, simplifying the products, and putting the customers to work (Ritzer 2007: 37-41). These arrangements construct the optimal means of achieving a given end in the workplace.

Streamlining the process makes the whole process of production to be an assembly line. Every movement and step of labour is pre-arranged scientifically in order to avoid the unnecessary waste of the workforce and any other resources. Therefore, from the very beginning of production till the product goes into customer's hand is designed to be a streamlined process.

Simplifying the products implies that the products are simple, fast and easy to prepare. The products of McDonald's are not only easy to prepare, they are also presented in a manner which makes it easy for the customers to order and to eat. Burgers, fries, and chicken nuggets are semi-prepared and can be cooked relatively quickly and without much complicated cooking skills. It is rather easy for the customers to order as well. McDonald's has a global menu of basically the same food, e.g. Big Mac, cheeseburger, hamburger, egg McMuffin and drinks. There are "easy to eat" snacks such as chicken nuggets. You do not need both your hands to enjoy chicken when you are driving. As a result of the simplification of the products, the labour process in McDonald's workplace become fragmented, de-skilled, easy to control, and highly replaceable. This is a major issue to be addressed later.

Putting the customers to work can be observed from the fast food, "self-service formula". The customers need to join the queue at the counter and place their order with the counter staff. Next, they wait for their food to be located into their tray, then, take their order away to look for seats within the premise in order to enjoy their meals. Upon finishing their meals, the customers normally clear the table by themselves and place the rubbish into the right bin. When the customers want to enjoy fast food without getting out of their cars, they have to follow the already designed tracks to order and pay at the first window, get their meals at the second one and leave.

\subsection{Calculability}

The second elements for fast food restaurants to achieve rationalisation are calculability. This means that items in the production process should be calculated and quantified. In a sense, calculability also means deploying nonhuman technologies to perform tasks in the given amount of time or make products of a given weight or size (Ritzer 2007: 57). The inevitable consequences it may cause are two-fold: focus on quantity rather than quality and on numbers.

\subsubsection{Quantity rather than quality}

Fast-food restaurants attract consumers by serving large portions. The Big Mac, whopper burger, double whopper burger or triple cheeseburger, large drinks or extra-large drinks. The customers are able request to "go large" for more 
French fried with a little extra money. Such emphasis on quantified products comparatively reduces the demand of quality and tend to become a surrogate for quality.

\subsubsection{Emphasis on numbers}

To simplify the various set meals, McDonald's puts numbers $1,2,3,4$ on the most ordered meals. This enables the workers to speed service and the customers can place their order quickly as well. For ethnic minorities who cannot use local language proficiently, such as foreign workers and new immigrants, can easily and precisely tell which meal they want. For example, 2 pieces chickens McCrispy meal, 9 pieces McNuggets are easy to identify from menus and take the order.

\subsection{Predictability}

In a rationalised society, the imperatives it may need is discipline, stability, order and consistency, because it is a society with predictability. In McDonaldised workplaces, in the first instance, predictability means that work organisation is not only a clean visible space. It is an environment that can be duplicated around the world. Second, predictability refers to script communications and interactions with the customers and among the workers.

\subsubsection{Transparency of workplaces}

To achieve predictability, in terms of organisational structure, workplaces need to be visually resemble and transparent. The consumers can see not only the working environment of the workers in the kitchen, but also activities of the other consumers in the restaurant. Moreover, managerial staffs can directly supervise everything that happens in the work place.

Due to emphasising the non-visual obstacle space, the working process is also resembled in McDonaldised workplaces. The working process is exposed to the consumers, the workers, and management in the transparent working arrangements. Working rules and structural arrangements in the workplaces of McDonald's make the workers act in a disciplined and standardised way in which not only the customers but also managerial staffs can predict what the workers are going to do next. The operation of assembly line production reinforces predictability of labouring and consuming behaviours.

\subsubsection{Scripting communications and interactions}

It indicates the repetitive and formal interactions between and among workers, management and consumers. Workers behave and act under the guidelines and instructions of the manual of McDonald's. For instance, the workers at the counter are required to carry out at least six steps in this work: Greet the customers, take the order, assemble the order, present the order, receive payment, deliver meals, thank the customers for choosing McDonald's and asking them to come again. The routinised and scripted interactions not only make workers' behaviour highly predictable; but also protect workers from insults and indignities that are frequently heaped upon them by the public. When encountering the public's hostility, workers can adopt the view that the scripts of McDonald's are the cause of the hostility instead of the workers themselves (Ritzer 2007:82).

Because the working manual has already scripted how to act and behave in the workplace, the communication and interaction can be consistently repeated and replicated. Even the workers are highly talented with language ability or social interaction, what they can deviate from the scripts to communicate and interact with others is very limited.

\subsection{Control}

McDonaldisation, to a large extent, implies about the development of managerial strategies in an attempt to gain control over workers and customers. The McDonaldised control do not simply adopt mechanic techniques to control the daily working process, but also employ sophisticated controlling methods to manage the behaviours of the key actors (e.g. the workers, the customers) in the McDonaldised workplace. As Ritzer (2007:101-2) puts it, once people are controlled, it is possible to begin reducing their behaviours to a series of machinelike actions. And once people behave as regularly as machines, the possibility of replacing them with actual machines such as robots would be greatly increased. Control through technology is the trend for managerial control over workers and their working process (Edwards 1980). I find that the methods of control in McDonald's can be divided into three aspects: technological control, structural control, and ideological control.

\subsubsection{Technological control}

In the workplace, the traditional control is face to face and direct, but is difficult and costly. It can easily lead to personal hostility and some form of resistance from the subordinates. However, controls made through technology are simple, less costly in the long run, and reduce hostility to supervisors in the workplace. (Ritzer, 2007: 102) To reduce conflict in the process of management, the methods of control in work places have been shifted from human face-to-face control to nonhuman technological control. This involves designing machinery and planning the flow of work to minimise the problem of transforming labour power into labour as well as to maximise the purely physically 
based possibilities of achieving efficiencies (Edwards 1980: 112). McDonald's and other fast food restaurants gain strong control over workers by developing a variety of automation in the process of production. For example, screening drink dispenser to avoid over filling drinks, auto-switch-off fries maker to avoid improper preparation, cashier of pressing pictures of meals or using bar codes to avoid errors in prices, swiping cards before and after duty to avoid faults in work records, installing CCTV to effectively supervise and observe activities of workers and customers. The application of these new technologies into work places radically changes the patterns and forms of labour process. What these devises want to achieve is not only controlling workers but also increases productivity and lowers the costs of operation. However, the unintended consequence of technological control is that workers are intensively controlled by these new technologies.

\subsubsection{Structural control}

Structural control is to supply controlling methods through the arrangement of work space and the organisational structure of work in attempts to dominate social relations and interactions in the workplaces. This method of control is much more sophisticated and subtle than Weber's (1958 [1921]) bureaucratic control. Furthermore, in the name of management, structural control disguises the control of capital over the labour process in order to simultaneously obscure and secure the surplus of values. In Weber's terms, bureaucratic control largely relies on hierarchical disciplines, written rules and nonhuman management and thus more emphasised on the control of organisational structures. By contrast, as mentioned earlier, structural control enhances supervision and control over activities and interactions of the key actors by manipulating the arrangement of space and social relation of production.

In spatial arrangements of McDonaldised workplaces, emphases are placed on transparency, brightness, discipline and regularity. Except for private areas such as toilets and staff offices, the spatial arrangements, including kitchen, service counter, dining area, and children's playing corner, can be seen without expression of visual obstacles. The communication and interaction between and among the managers, the workers and the consumers are transparent and truly exposed to the public. The potential consumers can see the activities in the workplace from outside, whilst the managers can not only supervise those in the work place, but also observe communications and interactions between workers and consumers. As a result, control and supervision are reinforced by such spatial arrangements and, in return, workers have to provide their services without a deviation from the working rules and the manual.

In terms of social relations in production, the transparency of spatial arrangement, scripted communication and interaction transformed the patterns of social relations and interaction in the workplaces into a controllable mode. They become formalised and simplified. The influences of sub-groups or informal groups in the workplace are weakened. The formation of trade union and its activities are hard to be organised. The introduction of new technologies such as CCTV and computers, has a great impact on the social relations of key actors in the workplaces by reinforcing the intensive controls and watch over them.

\subsubsection{Ideological control}

Ideological control refers to employ a variety of moral values and ideologies in accompany with the interests of employers to control the social relations and interactions of the key actors. The power and intensify of ideological control are much greater and more penetrative than that of technological or structural control. In McDonaldised workplaces, pre-work training and business culture are the source of value and moral controls through which the workers and the consumers would internalise the ideologies prompted by McDonald's value system (Ritzer, 1998: 62). These internalised ideologies, in turn, constrain the intentions of the workers and the customers to act at their will.

Human control is more likely to arouse resistance and hostility from workers (Friedman 1990). However, ideological control that internalises the value system of the employers into the workers would not only reduce the possibility of resistance and antagonism, but also make workers act as expected by the employers. In terms of efficiency and interests of operation, ideological control is better and more sophisticated than technological and structural control. Since an ideological control is the control by way of moral and value system, it is very difficult for the workers to cognitively liberalise from the ideology created by employers, unless the workers become aware of injustice and exploitation (McAdam 1988). This is the essential base for collective mobilisation of workers.

\section{The Possible Impacts of McDonaldisation}

In order to explore the extent to which the impacts of McDonaldisation on the labour process, it is necessary to identify the main themes of the labour process and then locate the key elements of McDonaldisation into the labour process. By doing so, one can address the connections between McDonaldisation and the labour process as well as explore its possible impacts on the workplaces. The main arguments of the labour process theory can be drawn from some important works in this field (i.e Braverman 1998; Thompson 1997; Burawoy 1985; Hyman, 1987; Edwards 1980). The core themes of the labour process theory can be categorised into four aspects: surplus value being generated by the labour process; the logic of accumulation driving capital constantly to revolutionise the production process; the necessity of control; structured antagonism between labour and capital (Thompson 1997: 241-245). Here, I do not want 
to intensively repeat these theoretical insights. Instead, my intention is to explore the impacts of McDonaldisation on the labour process by examining the extent to which and how the labour process is influenced by McDonaldisation.

\subsection{The double exploitation of surplus value}

Surplus value is generated from the labour process. To ensure labour power transforms into labour and to generate more surplus value, capital need to develop various strategies by occupying and exploiting the value of surplus produced by workers and coping with the possible obstacles and conflicts in the labour process. However, surplus value does not always come from capital, it come partly from the transformation of labour power. Marxists note that the way to accumulate capital is to appropriate surplus value by paying nothing to the workers. In other words, the exploitation of workers in the labour process is the way to secure accumulation of surplus value and make profits for capital.

To create more surplus value, the McDonaldised workplaces put the consumers into the labour process to do unpaid work when the consumers are unaware that their labour are at McDonald's disposal. The consequence of putting the consumers into the labour process is to bring about the redundancy of the workforce because some workers are replaced by the unpaid labour of the customers. Moreover, one of the vital strategies for accumulating surplus value is to minimise labour costs. In McDonald's, the fact that a great number of part-time workers or temporary workers are employed is a good example: reducing labour costs by replacing core workers (i.e. permanent workers) with part-time workers. Ritzer uses the term, McJobs, to portray the characteristics of the part-time jobs in the McDonaldised workplaces, which are temporary, non-skill, homogenous, tedious, fragmented, and high turnover rate. Therefore, the jobs are low-paid and marginalised staffed with young and minority workers. (Ritzer 1998: 59-61)

With the creation of "McJobs", "McWorkers" are largely employed. Since they are marginalised and highly substitutable workers, they are poorly protected by national regulations. The employers can employ McWorkers with great flexibilities and at their disposal. For instance, employers are able to increase the amount of McWorkers during peak hours, whilst asking workers to be off duty at the time of no customers. Therefore, it is difficult for McWorkers to foresee and estimate their regular incomes. With little protection of national laws, McWorkers could be made redundant at anytime without compensation for job losses when the workplaces are closed down.

McDonaldisation greatly increases the ability of employers to generate surplus value by making the customers to do unpaid labour. In this regard, one can claim that capital exploits the surplus value generated by not only the workers but also the consumers. Such a "double exploitation" of capital contributes to the concept of Marxian variable capital, which should embrace not just workers but also consumers. McJobs are simple, replaceable, fragmented and de-skilled. Therefore, they can not only be easily controlled, but also replaced with machines and temporary workers.

\subsection{Innovation of logic of accumulation}

A logic of accumulation constantly drives capital to revolutionalise the production process (Burawoy 1985; Littler 1990). As Thompson (1997: 243) argues that it arises not only from the competition between units of capital but also from the antagonism between capital and labour that is unique to capitalism as a mode of production. This logic of accumulation drives capital to enhance the capacity of transforming labour power to labour and reduces costs of production by de-skilling workers.

In terms of instrumental rationality, McDonaldisation not only suits the interests of capital but also reinforces its capability of capital accumulation. In pursuit of efficiency, the arrangements of the labour process such as streamlining the production, simplifying the products and putting the customers into work are deliberately developed by the employers rather than suddenly emerged in the workplaces.

In McDonaldised workplaces, the logic of accumulation also drives the development of new technologies and the new methods of production by improving the labour process with new technologies and replacing workers with new technological devises. To achieve this objective, it has to make the labour process fragmented and repetitive, which is the basis for machines to replace the workers. As a result, workers are alienated from the labour process and the products. Moreover, it widens the gap between the conception and execution of the labour process. The function of labour power is downgraded as those performing simply specialised task which serves to segmentalise the division of labour.

Globalised economic system driven by telecommunication and visual technology is developing faster than ever in the past decades, the boundaries to capital flow are broken down. Under the driving force of logic of accumulation, it is a necessity for capital to consistently search for methods of lowering costs and renovating technologies (Waters 2005: 150). This leads Burawoy (1985: 150) to stress that the fear of being fired is replaced by the fear of capital flight, plant closure, transfer of operations, and plant disinvestment. It is clear that the effects of McDonaldisation are widely multiplied by globalization and facilitate radical changes to the labour process. Workers are unable to defence themselves from the sweeping tides of McDonaldisation and globalisation. The double pressures of fearing losing their jobs and capital flight not only forces workers to conduct concessional bargaining, but also intensifies managerial intention of exploiting and controlling labour. 


\subsection{De-humanisation and De-personalisation}

As mentioned earlier, the methods of control in McDonaldised workplaces were categorised as threefold: technological control, structural control and ideological control. Even though Braverman (1998) stresses the importance of control, the controlling methods in McDonald's are more sophisticated and subtle than that identified by Braverman. The different methods of control in the McDonaldised workplaces have various impacts on the labour process.

Technological control follows the external coercive laws which extrinsically compel workers to act in a predictable way and consistent with the benefit of capital. Technological control not only makes the labour process de-humanised and de-skilled, but also infringes upon the human rights of workers. The installation of CCTV in the workplaces invades workers' privacy. People invent new technologies to replace manual operations, but in the end these technologies become the instruments of dominating people's lives. Human actions are restricted by new technologies, which is Marcus's (1964) strong argument on "one dimensional society". Based on this rationale, it can be argued that McDonaldisation brings about "one dimensional workplaces". It means that due to extremely emphasising instrumental or formal rationality, and neglecting the significance of communicative or substantive rationality, the daily work becomes dominated by single dimension of rationalisation.

Structural control adopts externally coercive instruments, which the workers have to work under the structural arrangements and constrains of the production process. In the context of almost transparent space, the managers can easily observe and supervise workers' behaviour; whilst the consumers and colleagues can observe communication and interaction among people in a convenient way. Small-sized work organisations shorten the communication distance between managers and workers. However, scripted communication and interaction restricts the formations of meaningful social relations between and among people. In McDonaldised workplaces, scripted communication and interaction make the workers accustomed to being guided what to do and how to talk and gradually losing their capability of explaining and define the situation they are in (Ritzer 1998: 24). In this sense, scripted interaction is a kind of instrumental action rather than communicative action, which is designed for the purpose of gaining controls over the labour process and increasing productivity. The actors including the workers, the managers and the customers hardly reach a mutual understanding through the use of languages of their own.

Ideological control completely differs from the above-mentioned methods of control. Instead of a externally coercive instrument, ideological control adopts a internally regulative instruments which make the workers internalise the ideologies developed by the employers to become the part of moral code for the workers. In this sense, when the workers and consumers intrinsically accept these values and ideologies, it is more likely for them to act as expectably as the employers. Based on this rationale, it can be assumed that if McDonald's can make the consumers view McDonald's as their own by developing "the sense or feeling of home" into the value system of McDonald's, it would be possible to further replace the workers in charge of the kitchen and the toilets with the unpaid labour of the consumers.

To sum up, the methods of control in the McDonaldised workplaces are such a sophisticated that the labour process as a whole can be influenced by technology, structure and ideology. However, the unintentional consequences of such controls may be caused: de-personalisation and de-humanisation.

\subsection{Deepening of structured antagonism}

The social relations of capital and labour is based on structured antagonism (Edwards 1987). The complex factors of the exploitation of labour, struggles for transforming labour power to labour, the demands for capital in controlling working conditions, and workers in pursuit of maximising wages bring about various forms of conflict and resistance in the workplace. Therefore, structured antagonism not only derives from the inherent confrontation between labour and capital, but also comes from conflicts of relationships within social structure of production.

The reasons why McDonaldisation might further deepens structured antagonism between capital and labour can be explained from two aspects: the increasing tendency of labour commoditisation and the opposition of collective interaction.

The tendency of labour commoditisation is a degree of orientation regarding workers as either commodities or human resource. Commodity and human resource are the two ends of a consistent spectrum. When employers view workers as commodity, workers receive low wages, poor fringe benefits, little training and less career prospect, and job insecurity. However, when employers see workers as human resources, workers enjoy higher wages, better fringe benefits, more training and promotion, and job security (Purcell and Ahstrand 1994: 178; Marchington and Parker 1990). In McDonaldised workplaces, the workers are seen as commodities. McWorkers can be hired and dismissed at the employers' will and work with low wages, poor fringe benefits as well as no career prospect. The employers enjoy the high degree of flexibility in adjusting the number of the workforce to meet the demand of markets. More McWorkers are employed during peak times, whilst only essential workers are on duty during off-peak times. Therefore, the status of "McWorkers" is regarded as the high orientation to labour commoditisation. 
McDonaldisation represents the combination between individualism and rationalism. Due to the asymmetry of power relations between capital and labour, the way in which workers can deploy to be a counter power against the employer is to unionise together and carry out collective action (Edwards 1987; Kelly 1998). From the views of the employers, interaction with collective workers and industrial actions of workers are irrational, putting the efficiency and flexibility of production at risks. Collective actions are beyond managerial controls. Unionism and collective actions stand in opposition to individualism and rationalism on which McDonaldisation is based. Therefore, individual interaction between workers and employers would be the best option for the employers to meet their interests. Without collective solidarity of workers, not only asymmetrical power relations between labour and capital will be maintained consistently, but also the control system over the workplaces will be sustained. As a result, the managerial strategies for industrial relation in the McDonaldised workplaces are similar, which opposes unionism to spread and penetrate into the workplaces and obstructs the control system from being demolished.

\section{Resisting McDonaldisation: Subjectivity and Flexibility}

As I mentioned earlier, the McDonaldisation thesis argues that contemporary working life is succumbing to the rationalisation, routinisation, and predictability. In the previous section, I demonstrated the possible impacts of McDonalisation on the labour process. In fact, despite the wave of McDonaldisation is hard to be resisted and even reversed, there are forces which seem likely to drive the workers and the labour process, to some degree, away from McDonaldisation, namely subjectivity and flexibility. Here, I move on to examine whether and the extent to which they operate to resist McDonaldisation.

\subsection{Subjectivity: Absolute Domination or Relative autonomy?}

Foucault (1988: 11-12) stress that, when the practices of labour is not invented by workers but constructed by others with their goals, values, and culture, the formation of subjective consciousness of workers would be suppressed. In this case, the behaviour and action of the workers would tend to be universal, consistent and rountinised, because they cannot actively generate and format the sense of "themselves" through practicing their labour for their own purposes. The question one may raise here is whether or not the practice of labour and the formation of subjectivity of workers in McDonald's are restricted or dominated by managerial controls and instrumental rationalities.

The special strategies for control and resistance adopted by managers and workers respectively are likely to oscillate between coercion and consent relying upon the specific market conditions (Ramsay 1978; Hyman 1987; Collinson, 1992). The relationship between labour and capital is a contradictory relationship of coexistence of both interdependence and antagonism (Edwards 1987; Littler 1990). In the context of contradictory relations, Hyman (1987: 30) even notes that, "there is no one best way of managing these contradictions, only different routes to partial failure". Therefore, managerial strategy can be best be conceptualised as the programmatic choice among alternative "none of which can prove satisfactory", because of workers' resistance. Collinson (1992) also argues that, no matter how subordinated workers are, workers always retain some social and technical knowledge and the resource to deploy a degree of control over their lives. They are conceived that due to subjectivity of workers, there is room or space available for workers to opt for the measures used to cope with industrial disputes at work.

Despite the asymmetrical relations of power between labour and capital, Giddens (1986) claims that, its nature remains dualistic: interdependence and reciprocal. Although control and domination exist in the workplaces, workers are able to retain a certain degree of inter-subjectivity, social relations, knowledge and technology. These characteristics are conducive for breaking the control and blockade the employers deploy. As Brown (1992: 192) notes, like other social processes, attempts to control the labour process must have unintended consequences which contradict with employers' original intentions. Therefore, the integration of the production process, which bases on the division of labour and control such as assembly line, has the possibility of being blocked and resisted by a small group of workers. That is, despite the sophisticated controls manipulated by the employers, workers are able to develop strategy for resistance, such as restricted output in the game of making-out (Burawoy 1985), joking by expressing their dissatisfaction in an attempt to undermine managerial authorities (Radcliffe-Brown 1965), fiddling their working time, theft or using facilities for personal purposes (Collinsons 1992; Noon and Blyton 2007).

In this sense, in McDonald's workplaces, McWorkers also retain some social and technical knowledge and resources enough to demonstrate their discontent with the employers' institutional arrangements and express their complaints over the variety of managerial controls. In spite of the routinised interactions and scripted communication required by McDonald's, it is difficult for employers to force McWorkers, who have grievances, to show their smiling faces all the time at work. In other words, the options remain available for McWorkers to either serve as an emotional labour of taking good care of the customs or simply act as a typical physical labour. Moreover, in some cases, it is also hard for the employer to avoid the spreading of devastating rumors at work which are intentionally exploited by the aggrieved McWorkers in an attempt to undermine managerial authorities, simply because they are unhappy with the introduction of a new working rule. In the other cases, it is not hard to imagine that McWorkers treat their visiting friends with free meals of the Big Mac burgers within the premise of McDonald's as the way of showing their friends that they are not 
just only a McWorker but are capable of doing what they want to do at the McDonald's premises. In some sense, it seems that, in turn, McWorkers get back the power of dominating production order in the workplace from the employers' hands.

Furthermore, in order to show their dissatisfaction with what the McDonald's system has done, McWorkers can take a last resort by a "voting-with-feet" option: leave their McJobs. As I mentioned earlier, there is a high labour turnover rate in the McDonald's workplaces. In some respects, it implies that McWorkers, who are regarded by their employers as the secondary workforces in the McDonald's workplace, can express what they really feel to their employers by quitting the McJobs.

To sum, on one hand, three dimensional controls of technology, structure, and ideology are sophisticatedly and elaborately employed by McDonald's in a bid to successfully obtaining workers' consent and co-operation which, in Marx's term, is vital for employers to transform labour power into labour. On the other hand, in terms of inherent conflicts between labour and capital, even subordinated McWorkers still have a selection of strategies and tactics used to resist managerial arrangements. Therefore, it is showed, though, that in the capitalist economy, McWorkers do not have enough powers and resources to stop employers' exploitation of labour and curb the spread of McDonaldisation into the other workplaces. However, they have a relative autonomy of determining the way they want, irrespective of its consequences. Despite the defenseless of McWorkers against McDonaldisation, the co-existence of and intertwining between managerial opposition and workers' resistance will never come to an end in the McDonaldised workplaces. Based on the discussion above, an implication drawn here is that, despite of the prevailing of McDonaldisation, the workers with subjectivities retain the relative autonomy to resist a variety of control.

\subsection{Flexibility: Colonisation of life world?}

Marshall (2007: 550-551) indicates that the nature of rationalisation is a process which actors intensify controls over the outside world by exercising their knowledge in the context of impersonal relationships. Rationalisation does not bring the freedom and autonomy for actors. Instead, a means of rationalisation is taken as its purpose, whereas actors are imprisoned in the "iron cage" of the system, organisation, and activities of rationalisation. The concept of "iron cage" here is closed to Haberma's (1987) "colonisation of life world". The colonisation of life world means that, due to the enforcement of instrumental rationality within economic and administrative systems, the reproduction of labour is threatened and social rationalisation become twisted and fragmented. In McDonaldised workplaces, because the instrumental rationality and control are excessively emphasised, the communicative rationality can not be reached through inter-subjectivities. This implies that, McWorkers are imprisoned in the iron cage of McDonaldisation and, even worse, face with the colonisation of working-life world.

However, Ritzer (2007: 154) argues that post-Fordism stands in opposition to the McDonaldisation thesis: the idea that there is an increase in irrationality contradicts the view that there is an increase in rationality. In post-Fordist societies, the regime of capital accumulation and the labour process are transited from mass accumulation to flexible accumulation (Harvey 1990). Mass accumulation needs rigid technologies, standardised work routines, homogeneous products, and de-skilling, whilst flexible accumulation requires sophisticated technologies, flexible production process, heterogeneous products, and various skills. Therefore, the rise of post-Fordism has a number of distinguishing characteristics, which are different from those of McDonaldisation, such as lean production, just-in-time, a more flexible form of management, interest in more customised and specialised products, and demands for workers with more diverse skills to handle the new and more sophisticated technologies. These facts are inconsistent with the fundamental tenets of McDonaldisation. In this sense, the iron cage of McDonaldisation does not completely block the flexible production in the era of post-Fordism. Instead, McDonald's working system needs to learn how to adapt to the dramatic changes of a global economy for surviving. The way of achieving this is to make their working system more flexible rather than rigid.

Among the things McDonaldism shares with Fordism are rationality, homogeneous products, efficiency and standardisation, deskilling, the mass worker, constraint and rigid technologies. However, with intensifying global competitions, McDonaldism has started to adopt some key concepts of post-Fordism for boosting the company's benefits and maximising capital accumulation. For instance, in order to enhance flexibility in employment, McDonald's has already introduced flexible working-time (i.e. part-time workers and temporary workers), performance-related payment based on a minimum wage, flexible work organisation (i.e. dismantaling job classifications, workers performing multiple tasks and promoting greater cooperation and team work). Therefore, it can not be denied that some vital elements of post-Fordism has influenced the way of McDonald's managerial strategies for regulating employment practices at present.

Drawing from the discussion above, it is clear that McDonaldisation do not fully dominate the labour process of the daily working life, whilst post-Fordism cannot help workers as a whole completely escape from "colonisation of working life". The dichotomy of patterns of the labour process between McDonaldism (or mass accumulation) and post-Fordism (or flexible accumulation) do not contradict each other but co-exist at the same time. 


\section{Conclusions}

McDonaldisation is the process of more and more sectors of the society dominated by the principles of managing fast food restaurants. The article linked McDonaldisation with the labour process by exploring its impacts on the labour process and showing the driving forces resisting the spread of McDonaldisation.

McDonaldisation reinforces the degree of managerial control over labour and expends the range of capitalist exploitation from workers to the "unpaid labour" -- the customers. In the labour process of McDonald's, the boundary between the consumer and the worker is gradually blurred and even eroded. The customers used to be the source of profit-making but are now asked to a part of the labour force. In essence, this is an exploitation of the consumers to supplement assist McDonaldisation in exploitation of labours. The experience of McDonald's reveals that the nature of work is changing, capitalism is developing new instruments to control and exploit labour. Not only can labour power be replaced with temporary workers and machines, but also to some extent with the customers. As Ritzer (1998: 70) puts it, surplus value is now not only derived from the labour time of the employee, but also from the leisure time of the consumer.

McDonaldisation can be seen as a movement of rationalisation, whose ultimate objective is to simultaneously obscure and secure surplus values during the labor process. The major impacts of McDonaldisation on the labour process are four aspects: double exploitation of surplus, innovation of a logic of accumulation, the possible constraints of subjectivity, and deepening of structured antagonism. Under the global economy, the impacts of McDonaldisation become profound and far-reaching. To reduce the uncertainty, McDonaldisation makes the labour process more streamlined, disciplined, orderly and consistent by exercising sophisticated controls. Moreover, it makes the production process more efficient, predictable and calculable by consistently improving the mode of production. As an open workplace, the imperative of McDonaldisation is domination, arbitrariness and instrumental rationality, which serve to enhance the efficiency, calculability, predictability and control of the labour process. Workers shape the sense of themsleves through their daily working life. Therefore, due to various working experiences of individuals, the subjectvity of McWorker is varied. The subjectivity of McWorkers encourage them to gain the power of setting "the rule of playing" at work rather than just follow the working disciplines required by employers. Despite the trendency of McDonaldisation, the subjectivity of the workers and the flexibility of production process operate to make social relations of the procduction more dynamic and pluralistic. McDonaldism shares the same arrangements with Fordism. With increasing global competitions, post-Fordism has emerged to penetrate into the McDonaldised workplaces. While McDonaldisation remains a powerful force in today's world, it will adapt to the rapid changes of global economy.

\section{References}

Berkeley-Thomas, A. (1993). Controversies in Management. London: Routledge.

Blackburn, R. P. Coombs, and R. Green, K. (1985). Technology, Economic Growth and the Labour Process. London: Macmillan.

Boyer, R. (1988). The Search for Labour Market Flexibility. Oxford: Clarendon.

Braverman, H. (1998). Labour and Monopoly Capital. New York: Monthly Review Press.

Burawoy, M. (1985). The Politics of Production. London: VERSO.

Collinson, D. (1992). Managing the Shopfloor. Berlin: de Gruyter.

Edwards, P. (1987). Conflict at Work: A Materialist Analysis. Oxford: Blackwell.

Edwards, R. (1980). Contested Terrain: The Transformation of the Workplace In the Twentieth Century. New York: Basic Books.

Foucault, M. (1988). The Ethic of Care for the Self as a Practice of Freedom. In J. Bernauer and D. Rasmussen (eds), The Final Foucault. Cambridge, Mass.: MIT Press.

Foucault, M. (1995). Discipline and Punish. New York: Vintage Books.

Friedman, A. (1990). Managerial Strategies and the Labour Process. In D.Knights and H. Willmott (eds), Labour Process Theory. London: Macmillan.

Giddens, A. (1986). The Constitution of Society. Cambridge: Polity.

Habermas, J. (1998). The Theory of Communicative Action, Vo1. I. Boston: Beacon Press.

Habermas, J. (1998). The Theory of Communicative Action, Vol. II. Boston: Beacon Press.

Harvey, D. (1990). The Condition of Postmodernity. London: Blackwell.

Hyman, R. (1987). "Strategy or Structure? Capital, Labour and Control”, Work, Employment and Society 1(1): 25-55.

Kelly, J. (1998). Rethinking Industrial Relations: Mobilization, Collectivism and Long Waves. London: Routledge. 
Littler, R. (1990). The Labour Process Debate: A Theoretical Review 1974-1988. In Knights, D. and Willmott, H. (eds), Labour Process Theory. London: Macmillan.

Marchington, M. and Parker, P. (1990). Changing Patterns of Employee Relations. London: Harvester Wheatsheaf.

Marcuse, H. (1991). One Dimensional Man: Studies in the Ideology of Advanced Industrial Society. Boston: Beacon Press.

Marshall, G. (2007). Oxford Dictionary of Sociology. Oxford: Oxford University Press.

McAdam, D. (1988). "Micromobilization Contexts and Recruitment to Activism", International Social Movement Research, 1: 1-10.

Noon, M. and Blyton, P. (2007). The Realities of Work. London: Macmillan.

Purcell, J. and Ahlstrand, B. (1994). Human Resource Management in the Multi-Divisional Company. Oxford: Oxford University Press.

Radcliffe-Brown, R. (1965). Structure and Function in Primitive Society. London: Cohen and West.

Ramsay, H. (1978). "Cycles of Control: Worker Participation in Sociological and Historical Perspective", Socilology, 11(3): 481-506.

Ritzer, G. (1998). The McDonaldization Thesis. London: Sage.

Ritzer, G. (2007). The McDonaldization of Society. London: Pine Forge Press.

Thompson, P. (1997). The Nature of Work: An Introduction to Debates on the Labour Process. London: macmillan.

Waters, M. (2005). Globalization. London: Routledge.

Weber, M. (1958). The Rational and Social Foundations of Music. Carbondale, IL: Southern Illionis University Press. [first published in 1921] 